\title{
Dolicocephalization in Cephalic Indices of Adult Yorubas of Nigeria
}

\author{
G. S. Oladipo, ${ }^{1}$ K. C. Anugweje, ${ }^{2}$ and I. F. Bob-Manuel ${ }^{1}$ \\ ${ }^{1}$ Department of Anatomy, Faculty of Basic Medical Sciences, College of Health Sciences, University of Port Harcourt, \\ Port Harcourt, Nigeria \\ ${ }^{2}$ University of Port Harcourt Health Centre, Port Harcourt, Rivers State, Nigeria
}

Correspondence should be addressed to G. S. Oladipo; oladipogabriel@yahoo.com

Received 17 September 2014; Accepted 18 November 2014; Published 3 December 2014

Academic Editor: Philipp Mitteroecker

Copyright (C) 2014 G. S. Oladipo et al. This is an open access article distributed under the Creative Commons Attribution License, which permits unrestricted use, distribution, and reproduction in any medium, provided the original work is properly cited.

\begin{abstract}
Cephalic index is an important parameter useful in establishing racial and sexual dimorphism. This study was carried out to determine the cephalic indices of adult Yorubas of age 18 to 40 years. One thousand and twenty (1020) Yoruba adults consisting of 493 males and 527 females were recruited randomly for the study. These were all residents of Port Harcourt, Rivers State of Nigeria. The mean cephalic index of Yorubas without reference to gender was $74.39 \pm 5.41$. Dominant and rare types of head shapes are dolicocephalic (68.33\%) and hyperbrachycephalic (5.00\%), respectively. The mean cephalic indices were $75.02 \pm 4.76$ (mesocephalic) in males and $73.75 \pm 5.13$ (dolicocephalic) in females. We conclude that Yoruba males are mesocephalic while Yoruba females are dolicocephalic. Besides, this study also reveals dolicocephalization tending towards mesocephalization amongst Yorubas. These findings will be very useful in forensic science, physical and medical anthropology, and clinical practice, most especially craniofacial surgery as it presents a characteristic feature of the head configuration for this Nigerian race.
\end{abstract}

\section{Literature Review}

Anthropometry deals with the measurement of physical sizes and shapes of human body [1]. Data obtained from such measurements have been very useful in differentiating people of different ethnic backgrounds, nutritional status, and gender. Several measurable anthropometric parameters or variables have been developed over the years for establishing possible differences amongst different groups.

Cephalic index is one of such very useful measurable anthropometric variables used in physical anthropology to determine geographical gender, age, and racial and ethnic variations. Comparison of changes in cephalic index between parents, offspring, and siblings gives clues to genetic transmission of inherited characters or traits which play a role in forensic science [2-4]. Argyropoulos and Sassouni [5] showed that morphological features of different races and ethnic groups are not randomly distributed but appear in geographic clusters.

Arguably, Cephalometry continues to be the most versatile technique in the investigation of the craniofacial skeleton because of its validity and practicality [6]. Cephalometry is associated with the morphological study of all the structures present in the human head. Cephalometry is the scientific measurement of the dimensions of the head usually through the use of standardized lateral skull radiographs [8]. Based on the above factors, anthropometric studies are conducted on the age, sex, and social or ethnic groups in certain geographical zones [2, 9-17].

Several studies have been conducted on the age, sex, and racial or ethnic groups in different geographical zones [1519]. These authors have sited various categories of cranium on the basis of head length, breadth, and index and described seven groups of crania.

Okupe et al. [20], in a comparative study of biparietal diameter (BPD) fetuses of some of the Nigerian ethnic groups and Caucasians, showed statistically significant differences until near term when the Nigerian fetuses showed consistently longer BPD.

Cussenot et al. (1990) reported that skeletal measurements were made as the basis of foetal anthropometry and age determination. In a related study, cephalic index varied 
TABLE 1: Distribution of head breadth in males and females.

\begin{tabular}{|c|c|c|c|c|c|c|}
\hline \multirow{2}{*}{ Head breadth $(\mathrm{cm})$} & \multicolumn{2}{|c|}{ Males } & \multicolumn{2}{|c|}{ Females } & \multicolumn{2}{|c|}{ Total } \\
\hline & Frequency & Percentage & Frequency & Percentage & Frequency & Percentage \\
\hline $11.01-12.00$ & 17 & 3.45 & - & - & 17 & 1.67 \\
\hline $12.01-13.00$ & 85 & 17.24 & 51 & 9.68 & 136 & 13.33 \\
\hline $13.01-14.00$ & 204 & 41.38 & 306 & 58.06 & 510 & 50.00 \\
\hline $14.01-15.00$ & 68 & 13.79 & 136 & 25.81 & 204 & 20.00 \\
\hline $15.01-16.00$ & 51 & 10.34 & 34 & 6.45 & 85 & 8.33 \\
\hline $16.01-17.00$ & 51 & 10.34 & - & - & 51 & 5.00 \\
\hline $17.01-18.00$ & 17 & 3.45 & - & - & 17 & 1.67 \\
\hline Total & 493 & 100 & 527 & 100 & 1020 & 100 \\
\hline
\end{tabular}

TABLE 2: Distribution of head length in males and females.

\begin{tabular}{lcccccc}
\hline \multirow{2}{*}{ Head length $(\mathrm{cm})$} & \multicolumn{2}{c}{ Males } & \multicolumn{2}{c}{ Females } & \multicolumn{2}{c}{ Total } \\
& Frequency & Percentage & Frequency & Percentage & Frequency & Percentage \\
\hline $17.01-18.00$ & 51 & 10.34 & 85 & 16.13 & 136 & 13.33 \\
$18.01-19.00$ & 238 & 48.28 & 187 & 35.48 & 425 & 41.67 \\
$19.00-20.00$ & 170 & 34.48 & 204 & 38.71 & 374 & 85 \\
$20.00-21.00$ & 34 & 6.90 & 51 & 9.68 & 100 & 1020 \\
\hline Total & 493 & 100 & 527 & 8.33 \\
\hline
\end{tabular}

with advancing gestational age with the highest and lowest being 81.5 and 78.0 at weeks 14 and 28, respectively [21].

Several studies have been carried out to classify head shapes based on cephalic index into four internationally acceptable categories that include dolicocephalic $(<74.9)$, mesocephalic (75-79.9), brachycephalic (80.0-84.9), and hyperbrachycephalic (85.0-89.9) [9,22]. A study has shown that the people of Gurung community of Nepal of India are brachycephalic with cephalic index of 80.42 [2]. Bhils and Barelas are mesocephalic (76.98 \& 79.80) [23, 24]. The Iranian people are predominantly brachycephalic and hyperbrachycephalic [4].

Besides being a predictor of fetal death, early transvaginal measurement of cephalic index had been used for the determination of Down syndrome fetuses [25].

The present study was aimed at determining the head dimensions and classification of head shape based on cephalic index of Yorubas residing in Port Harcourt of Rivers State, Nigeria, which could be used for the purposes of forensic investigation and clinical practice most especially craniofacial surgery.

\section{Materials and Methods}

Study Design. A cross-sectional survey of Yorubas resident in Port Harcourt of Rivers State was carried out. Subjects were randomly selected. All subjects were of Yoruba by both parents and genealogies and were between 18 and 40 years of age. A total of 493 males and 527 females were measured and their cephalic indices were determined. The research was carried out in Port Harcourt, Rivers State. The materials used were spreading caliper (none calibrated).

Anthropometric Measurement. The anatomical landmarks, glabellas, inions (I), and euryon (eu) were marked. The anatomical landmarks were defined as follows, gabella: a point above the nasal root between the eyebrows and intersected by mid-sagittal plane; euryon: the most lateral point placed on the side of the head; inion: the distal point most placed on the external occipital protuberance in the midsagittal plane.

Procedure. The method used for obtaining the cephalic index was Hrdlicka's method. All measurements were taken with the subjects sitting on a chair with head in anatomical position and measurements were taken in the nearest centimeter. The head length was measured as the maximum transverse diameter between the two euryons using a spreading caliper while head breadth was measured as the biparietal diameter [2]. Data were analyzed statistically and results presented in tabular form.

\section{Results}

The results of the present study are presented in Tables 1-5. A total of 1020 human subjects (Yorubas) were studied, of which 493 (48.33\%) were males and 527 (51.67\%) were females. The subjects' ages were between 18 and 40 years. Tables 1 and 2 show the percentage frequencies of the distributions of head breadth and head length, respectively. Table 3 represents the distribution of the cephalic indices of the Yorubas investigated while Table 4 contains the mean values of the head length, head width, and cephalic index of the study.

The mean head breadth was $13.68 \pm 1.08 \mathrm{~cm}$ and the mean head length was $18.89 \pm 0.83 \mathrm{~cm}$. For males, the mean head breadth and head length were $14.05 \pm 2.71$ and $18.88 \pm 0.78 \mathrm{~cm}$, respectively, while for females, the mean head breadth and head length were $13.79 \pm 0.74 \mathrm{~cm}$ and $18.92 \pm 0.89 \mathrm{~cm}$, respectively (Table 4 ). 
TABLE 3: Incidence of the cephalic index in males and females.

\begin{tabular}{|c|c|c|c|c|c|c|}
\hline \multirow{2}{*}{ Cephalic index } & \multicolumn{2}{|c|}{ Males } & \multicolumn{2}{|c|}{ Females } & \multicolumn{2}{|c|}{ Total } \\
\hline & Frequency & Percentage & Frequency & Percentage & Frequency & Percentage \\
\hline$<70$ & 153 & 31.03 & 136 & 25.81 & 289 & 28.33 \\
\hline 70.01-75.00 & 170 & 34.48 & 238 & 45.16 & 408 & 40.00 \\
\hline $75.01-80.00$ & 85 & 17.24 & 119 & 22.58 & 204 & 20.00 \\
\hline $80.01-85.00$ & 34 & 6.90 & - & - & 34 & 3.33 \\
\hline $85.01-90.00$ & 17 & 3.45 & 34 & 6.45 & 51 & 5.00 \\
\hline $90.01-95.00$ & 17 & 3.45 & - & - & 17 & 1.67 \\
\hline 95.01-100.00 & 17 & 3.45 & - & - & 17 & 1.67 \\
\hline Total & 493 & 100 & 527 & 100 & 1020 & 100 \\
\hline
\end{tabular}

TABLE 4: Descriptive statistics of anthropometric measurements of cephalic index of males and females.

\begin{tabular}{lccc}
\hline Parameter & & Mean (standard deviation) & Total \\
\hline Head breadth $(\mathrm{cm})$ & Males & Females & $13.68 \pm 1.08$ \\
Head length $(\mathrm{cm})$ & $14.05 \pm 2.71$ & $13.79 \pm 90.74$ & $18.89 \pm 0.83$ \\
Cephalic index & $18.88 \pm 0.78$ & $18.92 \pm 0.89$ & $72.12 \pm 5.41$ \\
Sample size & $75.02 \pm 4.78$ & $73.75 \pm 5.13$ & 1020 \\
\hline
\end{tabular}

$Z$-test: $P<0.05$.

TABLE 5: Comparative data on cephalic indices of various populations.

\begin{tabular}{lccc}
\hline Race/ethnic group & Cephalic index (mean \pm SD) & $N$ & References \\
\hline Kvangaja race & 79.50 & 100 & Basu (1963) [30] \\
Bhils race & 76.98 & 100 & Bhargava and Kher (1960) [23] \\
Barelias & 79.80 & 100 & Bhargava and Kher (1961) [24] \\
Gujarati & 80.81 & 500 & Shah and Jahhav, 2004 [2] \\
Ijaw males & $80.98 \pm 6.11$ & 63 & Oladipo and Olotu, 2006 [31] \\
Ijaw females & $78.24 \pm 6.33$ & 37 & Oladipo and Olotu, 2006 [31] \\
Igbo males & $79.04 \pm 5.75$ & 53 & Oladipo and Olotu, 2006 [31] \\
Igbo females & $76.83 \pm 4.94$ & Oladipo and Olotu, 2006 [31] \\
Urhobo males & $86.50 \pm 9.06$ & 47 & Oladipo and Paul, 2009 [32] \\
Urhobo females & $87.09 \pm 11.30$ & 250 & Oladipo and Paul, 2009 [32] \\
Itsekiri males & $94.41 \pm 34.44$ & 250 & Oladipo and Paul, 2009 [32] \\
Itsekiri females & $82.16 \pm 44.74$ & 250 & Oladipo and Paul, 2009 [32] \\
Ogoni males & $111.18 \pm 10.28$ & 250 & Oladipo et al., 2009 [16] \\
Ogoni females & $75.09 \pm 7.09$ & 400 & Oladipo et al., 2009 [16] \\
Yoruba males & $72.12 \pm 4.78$ & 400 & Present study \\
Yoruba females & $73.75 \pm 5.13$ & 493 & Present study \\
\hline
\end{tabular}

SD: standard deviation; $N$ : sample size.

The mean cephalic index was $72.12(\mathrm{SD}=5.41)$. The mean cephalic indices of males and females were $(75.02(\mathrm{SD}=4.78)$ and $73.75(\mathrm{SD}=5.13)$.

The head breadth, head length, and cephalic index between males and females were tested for significance. The mean difference in the head length, head breadth, and cephalic index (CI) between males and females was statistically significance $(P<0.05)$. Table 5 represents the cephalic indices of various ethnic groups previously investigated. A large number of them are Nigerian ethnic groups. Characteristic cephalic indices could be observed in the table for different populations.

\section{Discussion}

In the present study, the mean cephalic indices of Yoruba males and females resident in Port Harcourt are 75.02 \pm 4.76 and $73.75 \pm 5.13$, respectively. Thus, the Yoruba males fall within the mesocephalic head type while females are within the dolicocephalic type. The Yoruba population irrespective of gender with cephalic index of $72.12 \pm 5.41$ could be classified as dolicocephalic head type.The size of cephalic index varies significantly in different geographical zones. In tropical zones head form is longer (dolicocephalic) but in temperate zones, head form is more round (mesocephalic 
or brachycephalic [26]). Thus, the present classification of Yorubas (dolicocephalic) as observed in our study is in line with variations of cephalic index according to different geographical zones as reported by Bharati et al. [26].

Kondo et al. [27] showed that the head breadth will reach maximum at age of 14. They also showed that, in Japanese population, brachycephalization and secular changes in head length occur [27]. As previously reported, genetic and environmental factors account largely for variations in head shapes $[4,23,24,28]$. We postulate based on our observations (Table 5) that the head type observed for Yorubas in comparison with other populations within Sub-Saharan region is a true reflection of their location, Tropical Region of West Africa. Further investigation with larger population is however needed to establish this fact. Sparks and Jantz [29] however showed that there is a relatively high genetic component of head shape. This explains the different types of head shape seen in genders of the Yorubas.

\section{Conclusion}

The results of present survey show that, in general, the Yoruba people can be classified as dolicocephalic. There is however sexual dimorphism $(P<0.05)$ with males showing higher cephalic index than females (males 75.02, mesocephalic, and females 73.75, dolicocephalic). Besides, this study reveals dolicocephalization tending towards mesocephalization occurs amongst Yorubas. From the foregoing, the race but not gender of the deceased may be determined with head measurement. The overlapping distribution of head shape between males and female makes sex determination from the present study impossible. The knowledge from this study can be of great importance to anthropologist as well as forensic scientist. The values obtained here can also be of great importance to plastic surgeons when reconstructive surgery is essential. This study should be considered in forensic investigations and appropriate clinical practices.

\section{Conflict of Interests}

The authors declare that there is no conflict of interests regarding the publication of this paper.

\section{References}

[1] D. Poswillo, "Causal mechanism for craniofacial deformity," Journal of Tropical Pediatrics, vol. 44, pp. 973-977, 1963.

[2] G. V. Shah and H. R. Jahhav, "The study of cephalic index of students of Gurajat," Journal of Anatomical Society of India, vol. 53, no. 1, pp. 25-26, 2004.

[3] S. W. Lobo, T. S. Chandrashekhar, and S. Kumar, "Cephalic index of Gurung community of Nepal-an anthropometric study," Kathmandu University Medical Journal, vol. 3, no. 3, pp. 263-265, 2005.

[4] M. J. Golalipour, "The effect of ethnic factor on cephalic index in 17-20 years old females of north of Iran," International Journal of Morphology, vol. 24, no. 3, pp. 319-322, 2006.
[5] E. Argyropoulos and V. Sassouni, "Comparison of the dentofacial patterns for native Greek and American-Caucasian adolescents," American Journal of Orthodontics and Dentofacial Orthopedics, vol. 95, no. 3, pp. 238-249, 1989.

[6] G. T. McIntyre and P. A. Mossey, "Size and shape measurement in contemporary cephalometrics," European Journal of Orthodontics, vol. 25, no. 3, pp. 231-242, 2003.

[7] V. Grau, M. Alcañiz, M. C. Juan, C. Monserrat, and C. Knoll, "Automatic localization of cephalometric landmarks," Journal of Biomedical Informatics, vol. 34, no. 3, pp. 146-156, 2001.

[8] I. EI-Feghi, M. A. SidAhmad, and M. Ahmadi, Automatic Localization of Craniofacial Landmarks for Assisted Cephalometry, 2004.

[9] P. Williams, M. Ayson, J. E. Aussak et al., "Grays anatomy," in Skeletal System, pp. 607-612, Elbs with Churchill Livingstone, London, UK, 38th edition, 1995.

[10] M. J. Golalipour, K. Haudari, M. Jahanshahi, and M. R. Frahani, "The shapes of head and face in normal male newborns in South-east of Caspian sea (Iran-Gorgan)," Journal of Anatomical Society of India, vol. 52, pp. 28-31, 2003.

[11] M. J. Golalipour, M. Jahanshahi, and K. Haidari, “The variation of head and face shapes in female newborns in the South-East of the Caspian sea (Iran-Gorgan)," European Journal of Anatomy, vol. 9, no. 2, pp. 95-98, 2005.

[12] B. C. Didia and D. V. Dapper, "Facial nasal maxillary, mandibular and oro-facial heights of adult Nigerians," Oriental Journal of Medicine, vol. 17, no. 1, pp. 1-8, 2005.

[13] S. H. Garba, A. I. Numan, and I. G. Mishara, "Craniofacial classification of normal newborns in Maiduguri metropolis, Nigeria," International Journal of Morphology, vol. 26, no. 2, pp. 407-410, 2008

[14] H. B. Fawehinmi and A. M. Eroje, "Nasal index of Ogbia children and adolescents of Bayelsa State-Nigeria," Journal of Anatomical Science, vol. 2, no. 1, pp. 21-23, 2009.

[15] O. Joy, E. Ahmed, O. Gabriel, and E. Ezon-ebidor, "Anthropometric study of the facial and Nasal length of adult Igbo ethnic group in Nigeria," Internet Journal of Biological Anthropology, vol. 2, no. 2, 2009.

[16] G. S. Oladipo, E. J. Olotu, T. Osah, E. A. Osunwoke, J. S. Hart, and K. Ordu, "A comparative study of cephalic indices of Nigerian Ibibios and Efiks," J. Arts Culture, vol. 4, no. 1, pp. 6265, 2009.

[17] G. S. Oladipo, L. K. Yorkum, and P. D. Okoh, "Measurements of head circumference, intercanthal distances, canthal index and circumference interorbital index of Ikwerre school children in Nigeria," Journal of Natural Sciences Research, vol. 3, no. 4, pp. 16-20, 2013.

[18] I. P. Singh and N. K. Bharin, Craniometry Anthropometry, Kem Publishers, New Delhi, India, 1st edition, 1968.

[19] E. A. Osunwoke, G. S. Oladipo, K. S. Ordu, and C. W. Paul, "Anthropometric study of the cephalic and nasal indices of Ogu and Ikwerre people of Nigeria," Current Research Journal of Biological Sciences, vol. 4, no. 1, pp. 1-3, 2012.

[20] R. F. Okupe, O. O. Coker, and S. A. Gbajumo, "Assessment of fetal biparietal diameter during normal pregnancy by ultrasound in Nigerian women," British Journal of Obstetrics and Gynaecology, vol. 91, no. 7, pp. 629-632, 1984.

[21] D. L. Gray, G. S. Songster, C. A. Parvin, and J. P. Crane, "Cephalic index: a gestational age-dependent biometric parameter," Obstetrics and Gynecology, vol. 74, no. 4, pp. 600-603, 1989. 
[22] M. Del Sol, "Cephalic index in a group of mapuche individuals in the IX Region of Chile," International Journal of Morphology, vol. 23, no. 3, pp. 241-246, 2005.

[23] I. Bhargava and G. A. Kher, "An anthropometric study of central India Bhils of Dhar District of Madaya Pradesh," Journal of Anatomy Society of India, vol. 9, pp. 14-19, 1960.

[24] I. Bhargava and G. A. Kher, "A comparative anthropometric study of Bhils and Barelas of Central India," Journal of Anatomical Society of India, vol. 10, pp. 26-33, 1961.

[25] P. Rosati and L. Guariglia, "Early transvaginal measurement of cephalic index for the detection of Down syndrome fetuses," Fetal Diagnosis and Therapy, vol. 14, no. 1, pp. 38-40, 1999.

[26] S. Bharati, S. Som, P. Bharati, and T. S. Vasulu, "Climate and head form in India," American Journal of Human Biology, vol. 13, no. 5, pp. 626-634, 2001.

[27] S. Kondo, E. Wakatsuki, and H. Shibagaki, "A somatometric study of the head and face in japanese adolescents," Okajimas Folia Anatomica Japonica, vol. 76, no. 4, pp. 179-186, 1999.

[28] C. Susanne and P. D. Sharma, "Multivariate analysis of head measurements in Punjabi families," Annals of Human Biology, vol. 5, no. 2, pp. 179-183, 1978.

[29] C. S. Sparks and R. L. Jantz, "A reassessment of human cranial plasticity: Boas revisited," Proceedings of the National Academy of Sciences of the United States of America, vol. 99, no. 23, pp. 14636-14639, 2002.

[30] A. Basu, "Anthropometry of the kayasthas of Bengal," Journal of Anatomical Society of India, vol. 3, pp. 20-25, 1963.

[31] G. S. Oladipo and E. J. Olotu, "Anthropometric comparison of cephalic indices between the Ijaw and Igbo tribes," Global Journal of Pure and Applied Sciences, vol. 12, no. 1, pp. 137-138, 2006.

[32] G. S. Oladipo and C. W. Paul, "Anthropometric comparison of cephalic indices between the Urhobo and Itsekiri ethnic group of Nigeria," Global Journal of Pure and Applied Sciences, vol. 15, no. 1, pp. 65-67, 2009. 

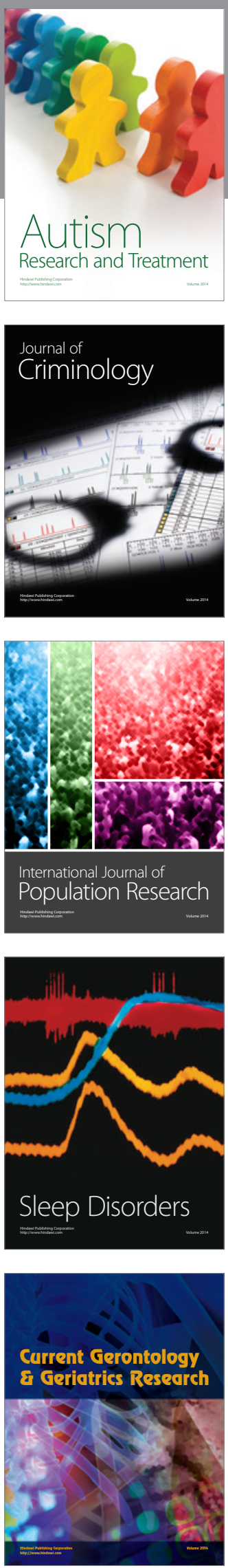
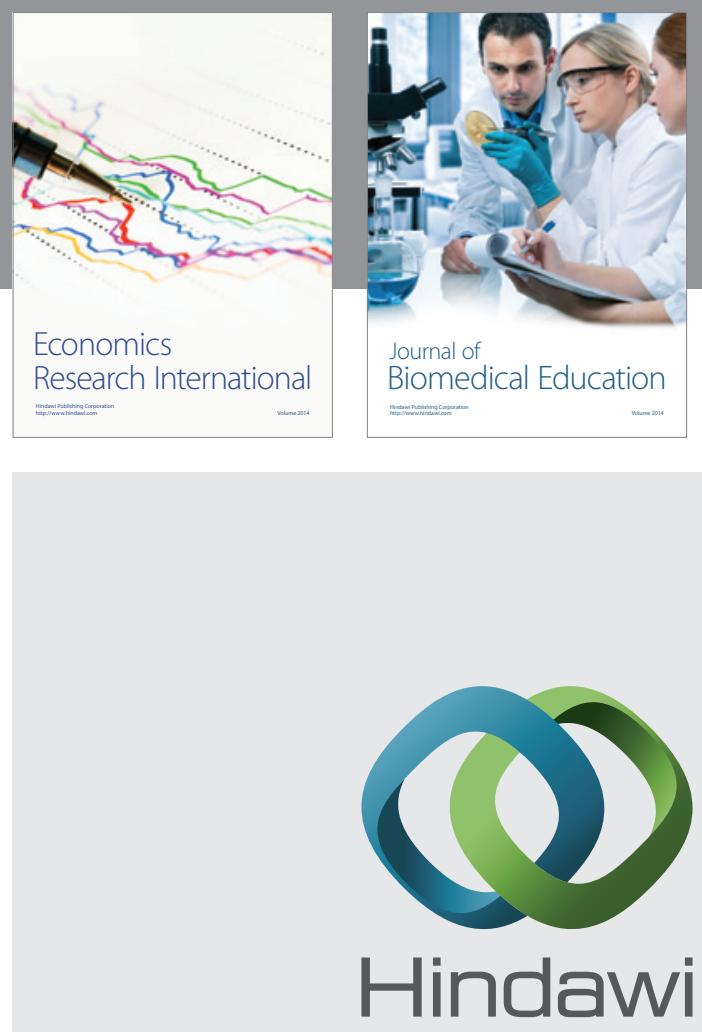

Submit your manuscripts at

http://www.hindawi.com
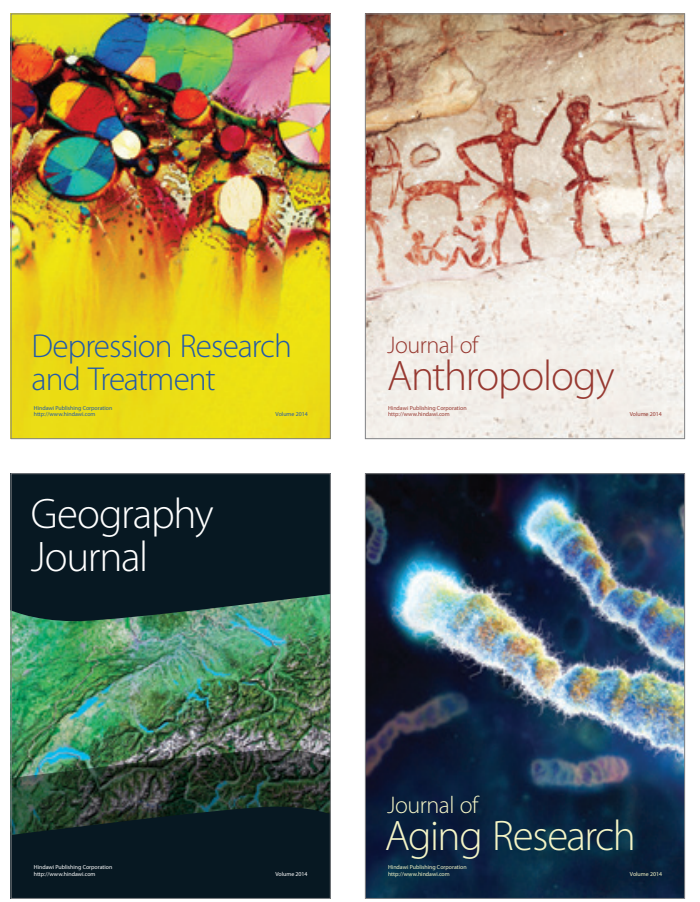
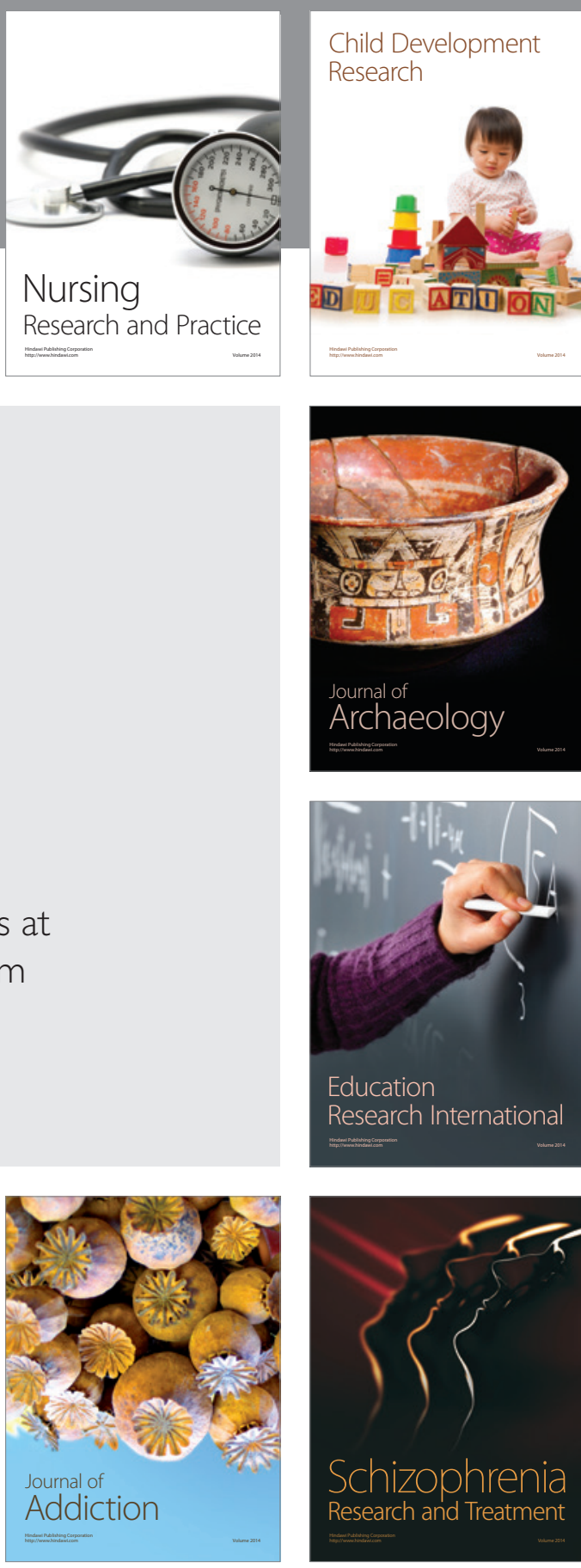

(D)
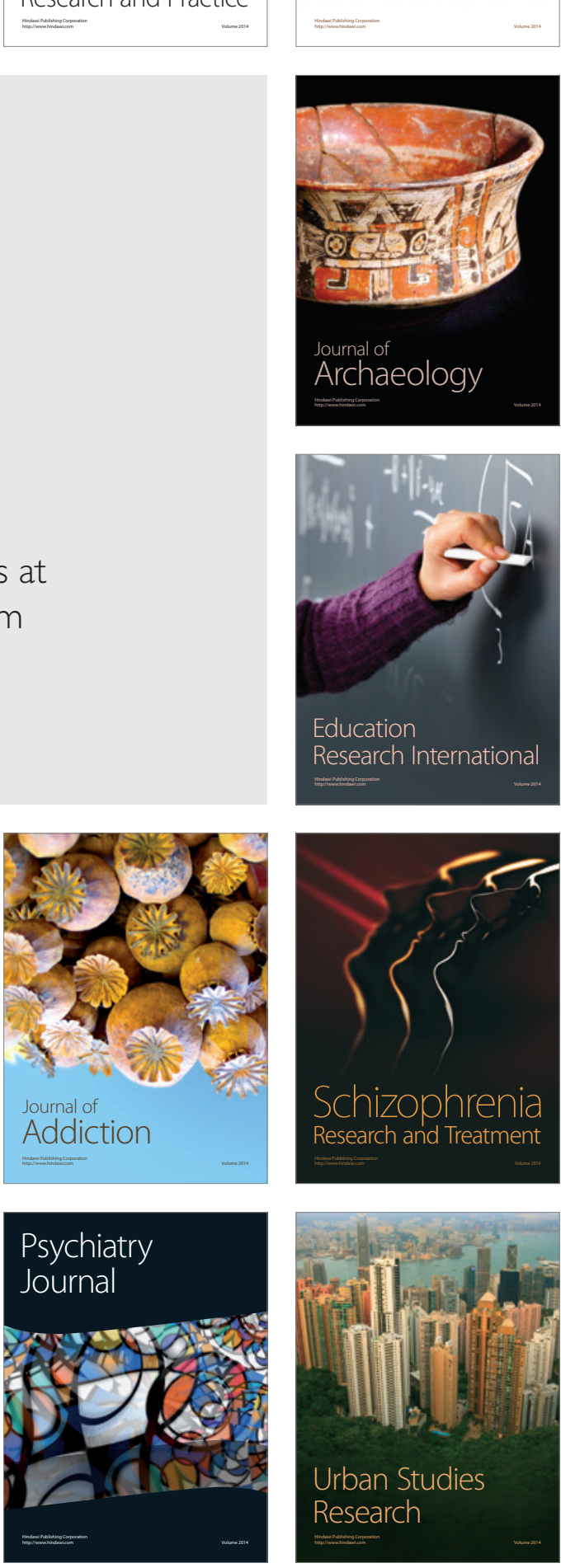